\title{
Ventricular volumes and body weight in mammals
}

\author{
J. P. HOLT, E. A. RHODE, AND H. KINES \\ Heart Research Laboratory, Department of Medicine, University of \\ Louisville School of Medicine, Louisville, Kentucky; and University \\ of California, School of Veterinary Medicine, Davis, California
}

Holt, J. P., E. A. Rhode, ANd H. Kines. Ventricular volumes and body weight in mammals. Am. J. Physiol. 215(3): 704-715. 1968.-Left and right ventricular end-diastolic (EDV), endsystolic (ESV), and stroke volumes, heart rates, cardiac output, total peripheral resistance (TPR), and other cardiovascular variables have been measured in the control state in nine species of mammals varying 1,790-fold (rat to horse) in body weight. The log-log relationships between these variables and body weight (BW), body surface, metabolic rate, heart weight, and ventricular weight have been determined and are described by power law equations. On the basis of these results relationships for each ventricle are described by equations in which ventricular volumes are related to $\mathrm{BW}^{1.0}$, heart rate to $\mathrm{BW}^{-0.25}$, cardiac output to $\mathrm{BW}^{0.75}$, and TPR to $\mathrm{BW}^{-0.75}$. Evidence is presented that in the control state the heart rate of mammals is a function of metabolic rate per unit body weight, and left ventricular stroke work per unit body weight is constant. It is concluded that the EDV, ESV, and stroke volumes of mammals are linear functions of body weight and not of body surface or metabolic rate; and that cardiac output is a linear function of metabolic rate and not a linear function of body surface area. It is suggested that ventricular volumes be reported as volume per unit body weight.

heart; cardiovascular equations; heart-body weight functions; cardiac output

I IV THE WIDE RANGE of mammals that have been studied (bat to elephant) body weight is inversely related to heart rate $(3,25)$ and directly related to blood volume and heart weight $(3,4,10)$. There is considerable evidence that cardiac output, which is the product of stroke volume and heart rate, is related to metabolic rate (13). For more than 100 years basal metabolism has been related to body surface (16), and since the studies of Grollman (12) relating cardiac output to body surface area, it has become the practice to report the cardiac output of man in terms of flow per square meter of body surface (28). In 1932 Kleiber $(21,22)$ and later Brody (2) in a study of the metabolism of a wide variety of mammals ranging from the mouse to the elephant, showed that basal metabolic rate was not related to body surface, which is a function of the two-thirds power of body weight, $\mathrm{BW}^{2 / 3}$, but is related to the $0.74 \pm 0.01$ power. On the basis of these studies Kleiber suggested that, in or: $x$ for data on the metabolism of mammals of different body sizes to be useful for the study of mammals in general, basal metabolic rate should be reported as a function of $\mathrm{BW}^{3 / 4}$. If the reporting of cardiac output per square meter of body surface is based on the assumption that cardiac output is related to metabolic rate, then it would appear more desirable to report cardiac output per $\mathrm{BW}^{3 / 4}$ than per body surface area (13). The primary reason, however, for reporting cardiac output as a function of any power of body weight should rest on mental evidence obtained in mammals extending uver a wide range of body size.

Assuming cardiac output to be a function of metabolic rate, then what functions of body weight or metabolic rate are heart rate and stroke volume, the product of which is cardiac output? In separate studies Clark (3) and Rihl (25) presented convincing evidence that, in mammals ranging 0.5 -millionfold in body weight, heart rate is a function of body weight raised to the $-0.26 \pm$ 0.01 power. In contrast, there appears to be little direct evidence as to whether stroke volume is a func:on of body weight or body surface. Some investigators have reported stroke volume as stroke index, i.e., stroke volume per square meter of body surface $(14,23)$, but insofar as we are aware there have been no studies extending over a wide range of mammals showing whether stroke volume is a function of body weight, body surface, or metabolic rate.

During recent years techniques for the measurement of right and left ventricular end-diastolic, EDV, and end-systolic, ESV, volumes have been develope: $(5,7$, $17,18)$ and several investigators have reported values for left ventricular EDV in man and the dog in terms of milliliters per square meter of body surface $(6,23)$. Since left and right ventricular end-diastolic volumes each comprise one component of the total blood volume, which is a function of body weight (4), it would be expected that end-diastolic volume is a function of body weight and not of body surface or metabolic rate. Likewise, since it has been shown in mammals whose heart weights varied 800 -fold that in the control state stroke volume is $43 \%$ of left ventricular EDV regardless of the size of the mammal (19), it would be expected that stroke volume is a function of body weight. 
In an earlier study of left ventricular volumes in mammals varying 54 -fold in body weight (dog to horse) we found no satisfactory relationship between EDV and body weight or heart weight (19). Since that time our left ventricular studies have been extended to include rabbits and rats as well as additional large mammals, and extend over a 1,790-fold range in body weight. In addition similar studies have been carried out on the right ventricle in mammals varying 334 -fold in body weight (rabbit to horse). These data are analyzed here in an attempt to determine the relationships between stroke volume, heart rate, cardiac output, EDV, ESV, strokework, peripheral resistance, and: body weight, heart weight, ventricular weight, body surface, and metabolic rate for the left ventricle and for the right ventricle.

\section{METHODS}

Experiments were carried out in the control state on 47 anesthetized and 10 unanesthetized mammals ranging from a $467-\mathrm{g}$ rat to an $836-\mathrm{kg}$ bovine. The left ventricle was studied in 10 anesthetized closed-chest horses (chloral hydrate, $85-169 \mathrm{mg} / \mathrm{kg}$ ), 2 cattle (chloral hydrate, 76$122 \mathrm{mg} / \mathrm{kg}$ ), 4 swine (chloral hydrate, $124-203 \mathrm{mg} / \mathrm{kg}$ ), 9 dogs (morphine, $3 \mathrm{mg} / \mathrm{kg}$; Dial-urethane, $1 / 8 \mathrm{ml}$ solution $^{1} / \mathrm{kg}$; pentobarbital, $7.5 \mathrm{mg} / \mathrm{kg}$ ), 7 rabbits (sodium pentobarbital, $18 \mathrm{mg} / \mathrm{kg}$; Dial-urethane, $0.3 \mathrm{ml}$ solution $/ \mathrm{kg}$ ), 3 rats (sodium pentobarbital, $55 \mathrm{mg} / \mathrm{kg}$ ), and 1 sea lion (Sernylan ${ }^{2} 0.75 \mathrm{mg} / \mathrm{kg}$; Dial-urethane $0.03 \mathrm{ml}$ solution $/ \mathrm{kg}$; pentobarbital $1.8 \mathrm{mg} / \mathrm{kg}$ ) and in 2 unanesthetized horses, 3 cattle, 3 sheep, and 2 goats. Additional anesthetic was given as needed during the course of an experiment. Experiments on the right ventricle were carried out only on anesthetized animals and included 7 horses, 1 bovine, 5 swine, 9 dogs, and 5 rabbits. The above drugs were chosen because they result in less change in heart rate than other commonly used anesthetics. The EDV, ESV, and stroke volume were measured by means of the electric conductivity indicatordilution technique described earlier $(17,18,20)$. In the measurement of left ventricular EDV a double-lumen electric conductivity catheter ${ }^{3}$ was passed through a carotid artery and the ascending aorta into the left ventricle in such a manner that one of the catheter tips lay approximately in the middle of the left ventricle, and the other, which contained the electric conductivity cell, lay in the ascending aorta a few millimeters from the aortic valve. The location was judged by the form of the pressure tracings obtained with Statham strain gauges, models P23A, D or G. From 0.03 to $4 \mathrm{ml}$ of concentrated $\mathrm{NaCl}$ solution was injected "instantaneously" into the left ventricle and the electric conductivity of the blood in he aorta recorded continuously with a six-channel Brush electromagnetic oscillograph. The concentration

${ }^{1}$ Ciba Pharmaceutical Co., Veterinary Sales Division, Summit, $\mathrm{J}$.

${ }^{2}$ Parke, Davis \& Co., Detroit, Mich. ${ }^{3}$ Fabricated by the US Catheter and Instrument Corp., Glens
alls, N.Y. of $\mathrm{NaCl}$ solution injected varied from 4 to $27 \%$ according to the size of the animal. In the measurement of right ventricular EDV a single-lumen electric conductivity catheter was passed via the external jugular vein, right atrium and ventricle into the pulmonary artery where the catheter tip was positioned a few millimeters from the pulmonary valve. Another catheter for injecting indicator was passed in a similar manner into the right ventricle where its tip lay near the atrioventricular valve.

In rats left ventricular fractional emptying curves, giving the ratio ESV/EDV, were obtained in a like manner employing a small-needle electric conductivity cell, ${ }^{4}$ similar to that originally described by White (30). The needle was passed into the ascending aorta by way of the left carotid artery. This system was not calibrated for absolute values and stroke volume was not measured. Instead, stroke volume was estimated from studies on cardiac output in rats of similar body weights (26), and the EDV calculated from the measured residual fraction and the estimated stroke volume.

Aortic pressure was measured either continuously or intermittently, and left and right ventricular pressures continuously, except for the fraction of a second when concentrated $\mathrm{NaCl}$ solution was injected into the ventricle. Pulmonary arterial pressure was measured intermittently. The levels and positions of the catheter tips in the animal were determined at autopsy and all pressures were referred to the level of the ventricular catheter tip as zero.

Stroke work was calculated by means of the equation:

$$
\mathrm{SW}=(\mathrm{SP}-\mathrm{EDP}) \mathrm{S}
$$

where SP is mean ventricular systolic pressure, EDP is ventricular end-diastolic pressure, and $\mathrm{S}$ is stroke volume. Total peripheral resistance was calculated from the equation:

$$
\mathrm{TPR}=\frac{\left[\left(\frac{\mathrm{AS}+\mathrm{AD}}{2}\right)-\mathrm{REDP}\right]}{\mathrm{CO}}
$$

where $\mathrm{AS}$ is aortic systolic pressure, $\mathrm{AD}$ is aortic diastolic pressure, REDP is right ventricular end-diastolic pressure, and $\mathrm{CO}$ is cardiac output. tion:

Body surface was calculated (in $\mathrm{cm}^{2}$ ) from the equa-

$$
\mathrm{BS}=\mathrm{KBW}^{2 / 3}
$$

where BW is expressed in grams and the value of $\mathrm{K}$ was $9.1,9.8,11.2,10.0,9.0$, and 9.0 for rats, rabbits, dogs, horses, swine, and cattle, respectively, and 9.8 for sheep, goats, and sea lions (8). The value for BS was corrected to square meters for the calculations given below. Basal metabolic rate, in kilocalories/24 hr, was calculated by

\footnotetext{
${ }^{4}$ Purchased from the Hamilton Co., Whittier, Calif.; or fabricated by the authors.
} 
TABLE 1. Power law and linear regression parameters for cardiovascular variables in mammals

\begin{tabular}{|c|c|c|c|c|c|c|c|c|c|c|c|c|c|c|c|c|c|c|c|c|c|}
\hline \multirow{3}{*}{ Variable, units } & \multicolumn{11}{|c|}{ Left Ventricle } & \multicolumn{10}{|c|}{ Right Ventricle } \\
\hline & \multirow[b]{2}{*}{$X$} & \multicolumn{7}{|c|}{ Power law coefficients } & \multicolumn{3}{|c|}{ Linear coefficients } & \multicolumn{7}{|c|}{ Power law coefficients } & \multicolumn{3}{|c|}{ Linear coefficients } \\
\hline & & $a$ & $b$ & $r$ & $\mathrm{~N}$ & $s_{a}$ & $S_{a}$ & $s_{b}$ & $A$ & $P$ & $\pm S$ & $a$ & $b$ & $r$ & $\mathrm{~N}$ & $s_{a}$ & $S_{a}$ & $s_{b}$ & $A$ & $P$ & $\pm S$ \\
\hline \multirow[t]{4}{*}{ EDV. $\mathrm{ml}$} & $\mathrm{BW}$ & 1.76 & 1.02 & 0.96 & 43 & 44 & 58 & 0.09 & 2.25 & 1.00 & 56 & 2.02 & 1.02 & 0.98 & 27 & 43 & 48 & 0.09 & 2.37 & 1.00 & 45 \\
\hline & $\begin{array}{l}\text { HW } \\
\text { VW }\end{array}$ & 0.68 & 0.94 & $\begin{array}{l}0.99 \\
0.99\end{array}$ & $\begin{array}{l}41 \\
31\end{array}$ & $\begin{array}{l}30 \\
26\end{array}$ & 33 & 0.05 & 0.51 & 1.00 & 38 & 0.71 & 0.94 & 0.99 & 27 & 28 & 26 & 0.05 & 0.53 & 1.00 & 27 \\
\hline & $\begin{array}{l}\mathrm{VW} \\
\mathrm{BS}\end{array}$ & $\begin{array}{l}0.97 \\
59.5\end{array}$ & $\begin{array}{l}0.93 \\
1.59\end{array}$ & $\begin{array}{l}0.99 \\
0.97\end{array}$ & $\begin{array}{l}31 \\
43\end{array}$ & $\begin{array}{l}26 \\
16\end{array}$ & $\begin{array}{l}30 \\
50\end{array}$ & $\begin{array}{l}0.05 \\
0.12\end{array}$ & 0.73 & 1.00 & 34 & & $\begin{array}{l}0.94 \\
1.57\end{array}$ & $\begin{array}{l}0.99 \\
0.98\end{array}$ & $\begin{array}{l}27 \\
27\end{array}$ & $\begin{array}{l}24 \\
16\end{array}$ & $\begin{array}{l}30 \\
38\end{array}$ & $\begin{array}{l}0.05 \\
0.12\end{array}$ & 2.42 & 1.00 & 32 \\
\hline & & $5 \times 10^{-3}$ & 1.37 & 0.96 & 43 & 107 & 58 & $\begin{array}{l}0.12 \\
0.12\end{array}$ & & & & $\begin{array}{l}65.2 \\
6 \times 10^{-3}\end{array}$ & $\begin{array}{l}1.57 \\
1.35\end{array}$ & $\begin{array}{l}0.98 \\
0.98\end{array}$ & $\begin{array}{l}27 \\
27\end{array}$ & $\begin{array}{r}10 \\
107\end{array}$ & $\begin{array}{l}38 \\
48\end{array}$ & $\begin{array}{l}0.12 \\
0.13\end{array}$ & & : & \\
\hline \multirow{6}{*}{ Stroke volume, $\mathrm{ml}$} & BW & 0.66 & 1.05 & 0.97 & 43 & 39 & & 0.08 & & & & & & & 27 & 44 & & & & & \\
\hline & HW & 0.26 & 0.96 & 0.99 & 41 & 29 & 32 & 0.05 & $\begin{array}{l}0.92 \\
0.21\end{array}$ & 1.00 & 50 & $\begin{array}{l}0.75 \\
0.25\end{array}$ & 1.04 & $\begin{array}{l}0.98 \\
1.00\end{array}$ & $\begin{array}{l}27 \\
27\end{array}$ & $\begin{array}{l}44 \\
23\end{array}$ & 49 & 0.10 & 0.99 & 1.00 & 44 \\
\hline & vw & 0.38 & 0.95 & 0.99 & 31 & 23 & 26 & 0.04 & $\begin{array}{l}0.21 \\
0.30\end{array}$ & i. .00 & 32 & $\begin{array}{l}0.25 \\
1.10\end{array}$ & $\begin{array}{l}0.97 \\
0.97\end{array}$ & $\begin{array}{l}1.00 \\
0.99\end{array}$ & 27 & 23 & $\begin{array}{l}22 \\
29\end{array}$ & $\begin{array}{l}0.04 \\
0.05\end{array}$ & $\begin{array}{l}0.22 \\
1.00\end{array}$ & $\begin{array}{l}1.00 \\
1.00\end{array}$ & $\begin{array}{l}22 \\
30\end{array}$ \\
\hline & BS & 24.4 & 1.62 & 0.98 & 43 & 15 & 44 & 0.11 & & 1.00 & 28 & $\begin{array}{l}1.10 \\
26.6\end{array}$ & $\begin{array}{l}0.97 \\
1.62\end{array}$ & 0.99 & 27 & 15 & 38 & $\left.\begin{array}{l}0.05 \\
0.12\end{array}\right]$ & & & 30 \\
\hline & MR & $2 \times 10^{-3}$ & 1.40 & 0.97 & 43 & 93 & 51 & 0.11 & & & & $2 \times 10^{-3}$ & 1.39 & 0.98 & 27 & 109 & 49 & 0.13 & & & \\
\hline & EDV & 0.40 & 1.01 & 1.00 & 43 & 16 & 20 & 0.03 & $0.42 \dagger$ & $1.00 \dagger$ & $19 \dagger$ & 0.37 & 1.02 & 0.99 & 27 & 23 & 23 & 0.05 & 0.43 & 1.00 & 22 \\
\hline \multirow{4}{*}{ Heart rate, beats/min } & BW & 236 & -0.25 & -0.90 & $46^{*}$ & 17 & 27 & 0.04 & 246 & -0.25 & 26 & 240 & -0.26 & -0.89 & 27 & 24 & 27 & 0.05 & 238 & -0.25 & 25 \\
\hline & $\mathrm{HW}$ & 322 & -0.24 & -0.95 & $43^{*}$ & 15 & 20 & 0.03 & 343 & -0.25 & 19 & 336 & -0.25 & -0.96 & 27 & 19 & 18 & 0.03 & 333 & -0.25 & 16 \\
\hline & BS & 99.9 & -0.38 & -0.91 & $46^{\circ}$ & 8 & 25 & 0.05 & & & & 98.5 & -0.41 & -0.91 & 27 & 10 & 25 & 0.08 & & & \\
\hline & $\begin{array}{l}\text { MR } \\
\text { EDV }\end{array}$ & $\begin{array}{l}959 \\
300\end{array}$ & $\begin{array}{l}-0.33 \\
-0.26\end{array}$ & $\begin{array}{l}-0.90 \\
-0.94\end{array}$ & $\begin{array}{l}46^{*} \\
43\end{array}$ & $\begin{array}{l}37 \\
16\end{array}$ & 27 & 0.05 & & & & $\underset{303}{10.5} \times 10^{2}$ & -0.35 & -0.89 & 27 & 56 & 27 & 0.07 & & & \\
\hline \multirow{5}{*}{ Cardiac output, $\mathrm{ml} / \mathrm{min}$} & & & $\begin{array}{r}-0.20 \\
0.79\end{array}$ & -0.94 & 43 & 16 & 20 & 0.03 & 289 & -0.25 & 19 & & -0.27 & -0.96 & 27 & 18 & 18 & 0.03 & 282 & -0.25 & 17 \\
\hline & $\begin{array}{l}\text { BW } \\
\text { HW }\end{array}$ & $\begin{array}{l}166 \\
89.2\end{array}$ & $\begin{array}{l}0.79 \\
0.70\end{array}$ & $\begin{array}{l}0.97 \\
0.98\end{array}$ & $\begin{array}{l}43 \\
41\end{array}$ & $\begin{array}{l}28 \\
32\end{array}$ & $\begin{array}{l}36 \\
35\end{array}$ & 0.06 & 209 & 0.75 & 37 & 179 & 0.78 & 0.98 & 27 & 28 & 31 & 0.06 & 214 & 0.75 & 30 \\
\hline & BS & $25 \times 10^{2}$ & $\begin{array}{l}0.70 \\
1.21\end{array}$ & $\begin{array}{l}0.98 \\
0.98\end{array}$ & $\begin{array}{l}41 \\
43\end{array}$ & $\begin{array}{l}32 \\
11\end{array}$ & $\begin{array}{l}35 \\
34\end{array}$ & 0.05 & 73.2 & 0.75 & 36 & & 0.72 & $\begin{array}{l}0.99 \\
0.99\end{array}$ & $\begin{array}{l}27 \\
27\end{array}$ & $\begin{array}{l}31 \\
11\end{array}$ & $\begin{array}{l}29 \\
26\end{array}$ & $\begin{array}{l}0.05 \\
0.08\end{array}$ & 73.0 & 0.75 & 29 \\
\hline & MR & 1.91 & 1.05 & 0.97 & 43 & 63 & $\begin{array}{l}34 \\
36\end{array}$ & $\begin{array}{l}0.08 \\
0.08\end{array}$ & 2.98 & 1.00 & 37 & $\begin{array}{c}26.3 \times 10^{2} \\
2.12\end{array}$ & $\begin{array}{l}1.21 \\
1.05\end{array}$ & $\begin{array}{l}0.99 \\
0.98\end{array}$ & 27 & 64 & 31 & $\begin{array}{l}0.08 \\
0.08\end{array}$ & 3.06 & 1.00 & \\
\hline & EDV & 119 & 0.75 & 0.98 & 43 & 23 & 27 & 0.04 & 122 & 0.75 & 25 & 113 & 0.76 & 0.98 & 27 & 29 & 29 & 0.06 & 120 & $\begin{array}{l}1.00 \\
0.75\end{array}$ & $\begin{array}{l}30 \\
26\end{array}$ \\
\hline \multirow[t]{6}{*}{ Stroke work, g-m } & BW & 0.59 & 1.15 & 0.98 & 31 & 49 & 57 & 0.10 & & 1.00 & 53 & 0.12 & & & & & & 0.10 & 0.24 & & \\
\hline & $\mathrm{HW}$ & 0.29 & 1.01 & $\begin{array}{l}0.96 \\
0.99\end{array}$ & 30 & 36 & 37 & 0.06 & $\begin{array}{l}1.32 \\
0.33\end{array}$ & $\begin{array}{l}1.00 \\
1.00\end{array}$ & $\begin{array}{l}53 \\
35\end{array}$ & 0.05 & $\begin{array}{l}1.14 \\
1.01\end{array}$ & $\begin{array}{l}0.98 \\
0.98\end{array}$ & $\begin{array}{l}21 \\
21\end{array}$ & $\begin{array}{l}44 \\
55\end{array}$ & $\begin{array}{l}44 \\
48\end{array}$ & $\begin{array}{l}0.10 \\
0.09\end{array}$ & $\begin{array}{l}0.24 \\
0.06\end{array}$ & $\begin{array}{l}1.00 \\
1.00\end{array}$ & 52 \\
\hline & VW & 0.45 & 1.00 & 0.99 & 25 & 32 & 34 & 0.06 & 0.47 & 1.00 & 32 & 0.26 & 0.99 & 0.97 & 21 & 49 & 57 & 0.11 & 0.28 & $\begin{array}{l}1.00 \\
1.00\end{array}$ & $\begin{array}{l}38 \\
42\end{array}$ \\
\hline & BS & 31.3 & 1.76 & 0.98 & 31 & 19 & 49 & 0.13 & & & & 6.28 & 1.75 & 0.99 & 21 & 18 & 40 & 0.14 & & & 42 \\
\hline & MR & $9 \times 10^{-4}$ & 1.53 & 0.98 & 31 & 118 & 57 & 0.13 & & & & $2 \times 10^{-4}$ & 1.52 & 0.98 & 21 & 111 & 44 & 0.13 & 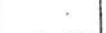 & & \\
\hline & EDV & 0.52 & 1.05 & 0.99 & 31 & 26 & 29 & 0.05 & 0.71 & 1.00 & 29 & 0.08 & 1.08 & 0.98 & 21 & 52 & 48 & 0.10 & 0.12 & 1.00 & 43 \\
\hline ESV, $\mathrm{ml}$ & EDV & 0.59 & 0.99 & 1.00 & 43 & 12 & 14 & 0.02 & $0.58 \dagger$ & $1.00 \dagger$ & $14 \dagger$ & 0.62 & 0.98 & 1.00 & 27 & 16 & 16 & 0.03 & 0.57 & 1.00 & 16 \\
\hline TPR, dynes-sec $\mathrm{cm}^{-6}$ & BW & $487 \times 10^{2}$ & -0.76 & -0.98 & 24 & 26 & 30 & 0.06 & $491 \times 10^{2}$ & -0.75 & 30 & & & & & & & & & & \\
\hline Heart wt, $g$ & BW & 2.61 & 1.10 & 0.98 & $43^{*}$ & 31 & 47 & 0.07 & 4.34 & 1.00 & 46 & 3.19 & 1.07 & 0.97 & 27 & 49 & 55 & 0.11 & 4.72 & 1.00 & 45 \\
\hline \multirow[t]{2}{*}{ Ventricle wt, g } & BW & 1.65 & 1.11 & 0.98 & $33^{*}$ & 35 & 52 & 0.08 & 2.83 & 1.00 & 49 & 0.74 & 1.06 & 0.96 & 27 & 58 & 66 & 0.12 & 1.10 & 1.00 & 54 \\
\hline & $\mathrm{HW}$ & 0.63 & 1.00 & 1.00 & $33^{*}$ & 6 & 7 & 0.01 & 0.64 & 1.00 & 7 & 0.22 & 1.00 & 1.00 & 27 & 15 & 14 & 0.03 & 0.22 & 1.00 & 15 \\
\hline
\end{tabular}
Power law parameters and linear regression coefficients for various cardiovascular variables and: body weight (BW), heart weight (HW), ventricular weight

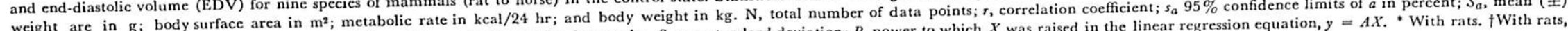
weight are in $\mathrm{g}$; body surface area in $\mathrm{m}^{2}$; metabolic rate in $\mathrm{kcal} / 24 \mathrm{hr}$; and body
standard error of the estimate in percent; $s_{b}, 95 \%$ confidence limits of $b$ in slope units. $S$, one standard deviation; $P$, power to which $X$ was raised in the linear regression equation, $y=A X$. "With rats. $f$ ith rats, standard
$\mathrm{N}=46$. 
the equation given by Kleiber (21):

$$
\mathrm{MR}=70 \mathrm{BW} 0.75
$$

where BW is expressed in kilograms.

In some experiments simultaneous measurements of volume and pressure were made on the two ventricles, and in addition to control observations some of the animals were subjected to plethora and hemorrhage. These studies will be described in another report. Digital Computer. The performed on an IBM 1130 10 logarithms and The data were transformed to base values calculated by linear regression of the logarithmic the parameters in the mod least squares to give the parameters in the power-law formula:

$$
y=a X^{b}
$$

Linear regression equations were determined by the method of weighted regression lines through the origin
to give the equation:

$$
y=A X
$$

where $X$ is a parameter such as body weight raised to one of the following powers: $1.0,0.75,-0.75$, or -0.25 . $y$ is any variable; $X$ is mass of body weight in kilograms, heart weight or ventricular weight in grams, body surface in square meters, metabolic rate in kilocalories/24 $\mathrm{hr}$, or end-diastolic volume in milliliters. Statistical analysis of the logarithmic equations included: the correlation coefficient $(r), 95 \%$ confidence limits for repeated line fits $\left(s_{a}\right.$ and $\left.s_{b}\right)$, and the standard error of the estimate $\left(S_{a}\right)$ which has much the same significance for a logarithmic regression line as a standard deviation for a mean, i.e., $2 S_{a}$ limits should include $95 \%$ of the cases. With log-log analysis $+S_{a}$ and $-S_{a}$ differ slightly; the values shown in the Tables are the mean of the two values. The standard deviation, $S$, was calculated for
the linear regression equations.

\section{RESULTS}

Table 1 presents the coefficients for the power law and the linear regression equations, as well as the statistical measures for the relationships of the cardiovascular variables to: body weight, heart weight, ventricular weight, body surface, metabolic rate, and end-diastolic volume. In the results described below for the left ventricle, extending from the rat to the bovine, the range in body weight and heart weight was 1,790- and 3,181-fold, respectively; the range for the right ventricle,-extending from the rabbit to the horse was 334 - and 716-fold, respectively. In Table 2 the average values for BW, BS, $\mathrm{EDV} / \mathrm{BW}, \mathrm{EDV} / \mathrm{BS}, \mathrm{S} / \mathrm{BW}, \mathrm{S} / \mathrm{BS}$, and heart rate, $\mathrm{R}$, for each class of mammals studied are given.

The values of the cardiovascular variables for man shown in Figs. 1-6 were taken from the reports of Bartle and Sanmarco (1), and Freis et al. (9), and calculated for an average individual having a body weight of $70 \mathrm{~kg}$, body surface of $1.8 \mathrm{~m}^{2}$, metabolic rate of $1,694 \mathrm{kcal} / 24 \mathrm{hr}$, heart weight of $315 \mathrm{~g}$, left ventricular weight of $203 \mathrm{~g}$, and right ventricular weight of $67 \mathrm{~g}$.

$E D V, E S V$, stroke volume, and heart rate. The logarithmic relationships between EDV, which varied over a 742and 597-fold range for the left and right ventricles, respectively, and: ESV, stroke volume, and heart rate

TABLE 2. Average values for cardiovascular variables and body weight and body surface in mammals

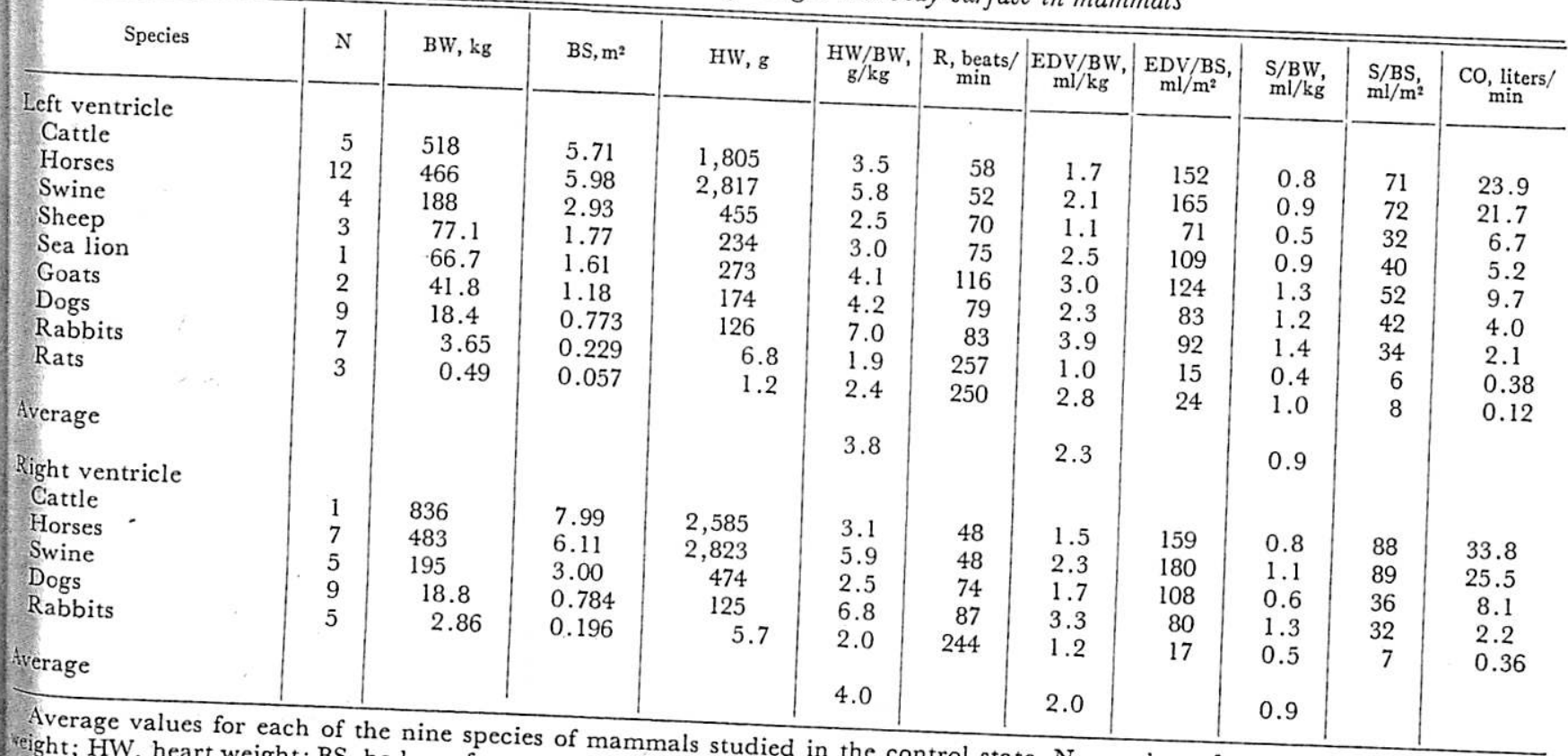

ight; HW, heart weight; BS, body surface area; $\mathrm{R}$, heart rate; EDV end-diastolic state. $\mathrm{N}$, number of animals studied; BW, body 
are shown in Fig. 1 and Table 1. These relationships are described by the equations:

$$
\begin{aligned}
\mathrm{ESV}_{\mathrm{L}} & =0.59 \mathrm{EDV}_{\mathrm{L}}{ }^{0.99} \\
\mathrm{~S}_{\mathrm{L}} & =0.40 \mathrm{EDV}_{\mathrm{L}}^{1.01} \\
\mathrm{R} & =300 \mathrm{EDV}_{\mathrm{L}}^{-0.26}
\end{aligned}
$$

$$
\begin{aligned}
\mathrm{ESV}_{\mathrm{R}} & =0.62 \mathrm{EDV}_{\mathrm{R}^{0.98}} \\
\mathrm{~S}_{\mathrm{R}} & =0.37 \mathrm{EDV}_{\mathrm{R}}^{1.02} \\
\mathrm{R} & =303 \mathrm{EDV}_{\mathrm{R}}^{-0.27}
\end{aligned}
$$

As shown in the equations ESV and stroke volume are related to EDV raised to approximately the first power, while heart rate is related to EDV raised to approximately the minus one-fourth power. There was little scatter of the data, one standard deviation being less than $\pm 23 \%$ in each relationship as shown in Table 1 .

$E D V$, body weight, heart weight, ventricular weight, body surface, and metabolic rate. The logarithmic relationships between EDV, and: body weight, heart weight, body surface, and metabolic rate are shown in Fig. 2, $A-D$, and Table 1 , and the average values are given in Table 2.

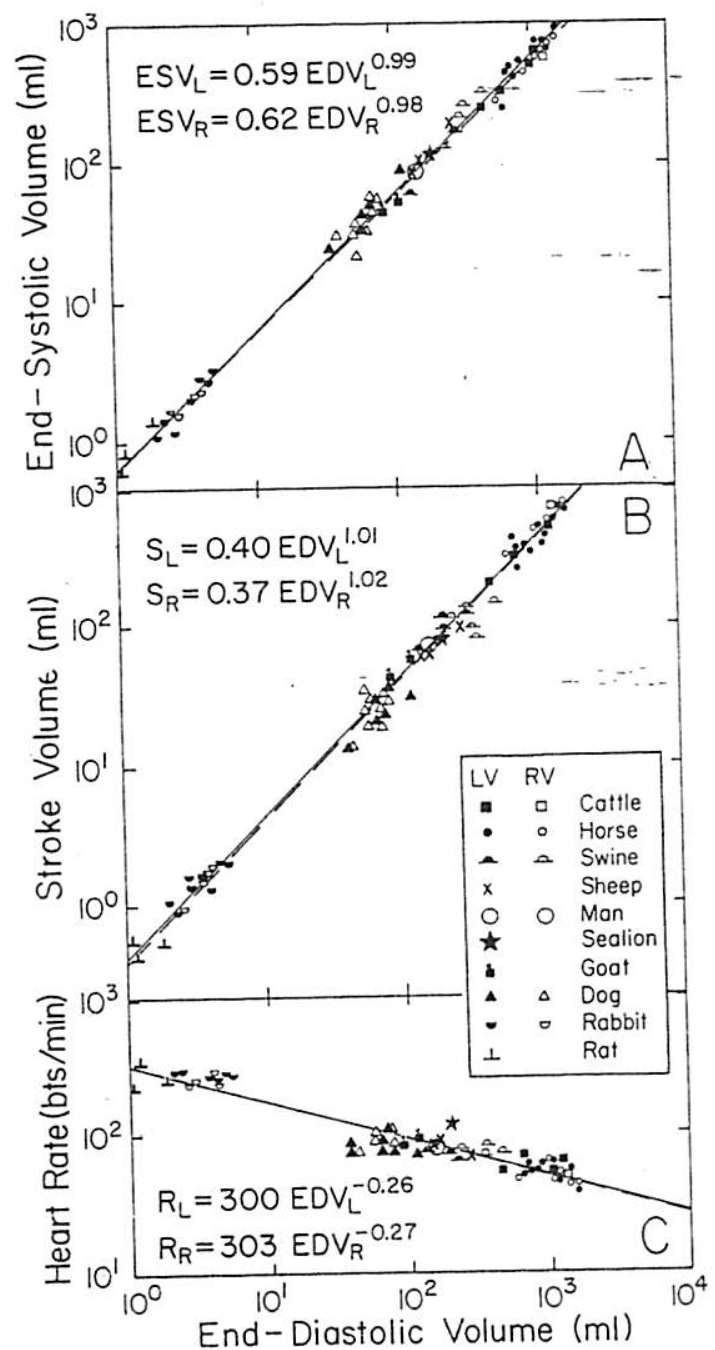

FIG. 1. Logarithmic relationships between end-diastolic volume and end-systolic volume, stroke volume and heart rate for the right and left ventricles of nine species of mammals (rat to horse) in the control state. Solid line, left ventricle; broken line, right ventricle. Subscripts $L$ and $R$ indicate left and right ventricles, respectively.
These relationships are described by the equations:

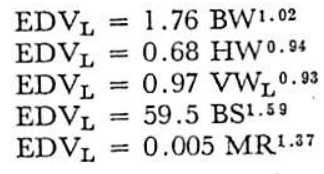

The scatter of the data was greater in the relationships to body weight than in the relationships to heart weight and ventricular weight. It should be noted that neither right nor left ventricular EDV are linear functions of body surface; instead, both are functions of body surface raised to the $1.58 \pm 0.01$ power and of metabolic rate raised to the $1.36 \pm 0.01$ power. Likewise, in Table 2 the average value of EDV/kilogram of body weight, extending over the wide range of mammals studied, is approximately constant, i.e., $2.3 \pm 0.9(1 \mathrm{sD})$ and $2.0 \pm 0.8(1$ $\mathrm{SD}) \mathrm{ml} / \mathrm{kg}$ for the left and right ventricles, respectively. In contrast the average value of $\mathrm{EDV} / \mathrm{BS}$ ranged from 15 to $165 \mathrm{ml} / \mathrm{m}^{2}$ body surface area from the rabbit to the horse. Thus, EDV appears to be linearly related to body weight, i.e., $\mathrm{BW}^{1.0}$.

Stroke volume, body weight, heart weight, body surface, and metabolic rate. The logarithmic relationships between stroke volume, which varied 776 - and 822 -fold, respectively, for the left and right ventricles, and: body .eight, heart weight, body surface, metabolic rate, and left ventricular weight are shown in Fig. 2, $E-H$, and Table 1 ; and the average values are given in Table 2. These relationships are described by the equations:

$$
\begin{aligned}
& \mathrm{S}_{\mathrm{L}}=0.66 \mathrm{BW}^{1.05} \\
& \mathrm{~S}_{\mathrm{L}}=0.26 \mathrm{HW}^{0.96} \\
& \mathrm{~S}_{\mathrm{L}}=0.38 \mathrm{VW}_{\mathrm{L}}{ }^{0.95} \\
& \mathrm{~S}_{\mathrm{L}}=24.4 \mathrm{BS}^{1.62} \\
& \mathrm{~S}_{\mathrm{L}}=0.002 \mathrm{MR}^{1.40}
\end{aligned}
$$$$
\begin{aligned}
& \mathrm{S}_{\mathrm{R}}=0.75 \mathrm{BW}^{1.04} \\
& \mathrm{~S}_{\mathrm{R}}=0.25 \mathrm{HW}^{0.97} \\
& \mathrm{~S}_{\mathrm{R}}=1.10 \mathrm{VW}_{\mathrm{R}}^{0.97} \\
& \mathrm{~S}_{\mathrm{R}}=26.6 \mathrm{BS}^{1.62} \\
& \mathrm{~S}_{\mathrm{R}}=0.002 \mathrm{MR}^{1.29}
\end{aligned}
$$

The scatter of the data was greater in the relationships to body weight than to heart weight and ventricular weight. It should be noted that stroke volume is not a linear function of body surface; instead it is a function of body surface raised to the 1.62 power and metabolic rate raised to the 1.4 power. Likewise in Table 2 the average value for stroke volume per kilogram body weight, extending over the wide range of mammals studied, is approximately constant, i.e., $0.9 \pm 0.3$ ( $\mathrm{sD}) \mathrm{ml} / \mathrm{kg}$ for both ventricles. In contrast, the verage values of stroke volume per unit body surface area ranged from 6 to 72 , and from 7 to $89 \mathrm{ml} / \mathrm{m}^{2}$ from the rabbit to the horse for the left and right ventricles, respectively Thus, stroke volume appears to be linearly related to body weight, i.e., $\mathrm{BW}^{1.0}$.

Heart rate, body weight, heart weight, body surface, an metabolic rate. The logarithmic relationships between hear rate, which varied over a seven- and eightfold range respectively, for the right and left ventricles, an !: bod weight and heart weight, are shown in Fig. 3 and able 
94

.94

.35

nships

weight seither ons of ;urface ic rate e 2 the :xtendoproxi0.8 (1 ctively. rom 15 to the to body

ace, and Jetween respecweight, and left d Table ?. Tlese

tionships ntricular is 1 ot a function netabolic ole 2 the am body nammals \pm 0.3 (1 $\approx$ average ea ranged rabbit to pec vely. related to urface, and veen heart old range, and: body id Table 1 .

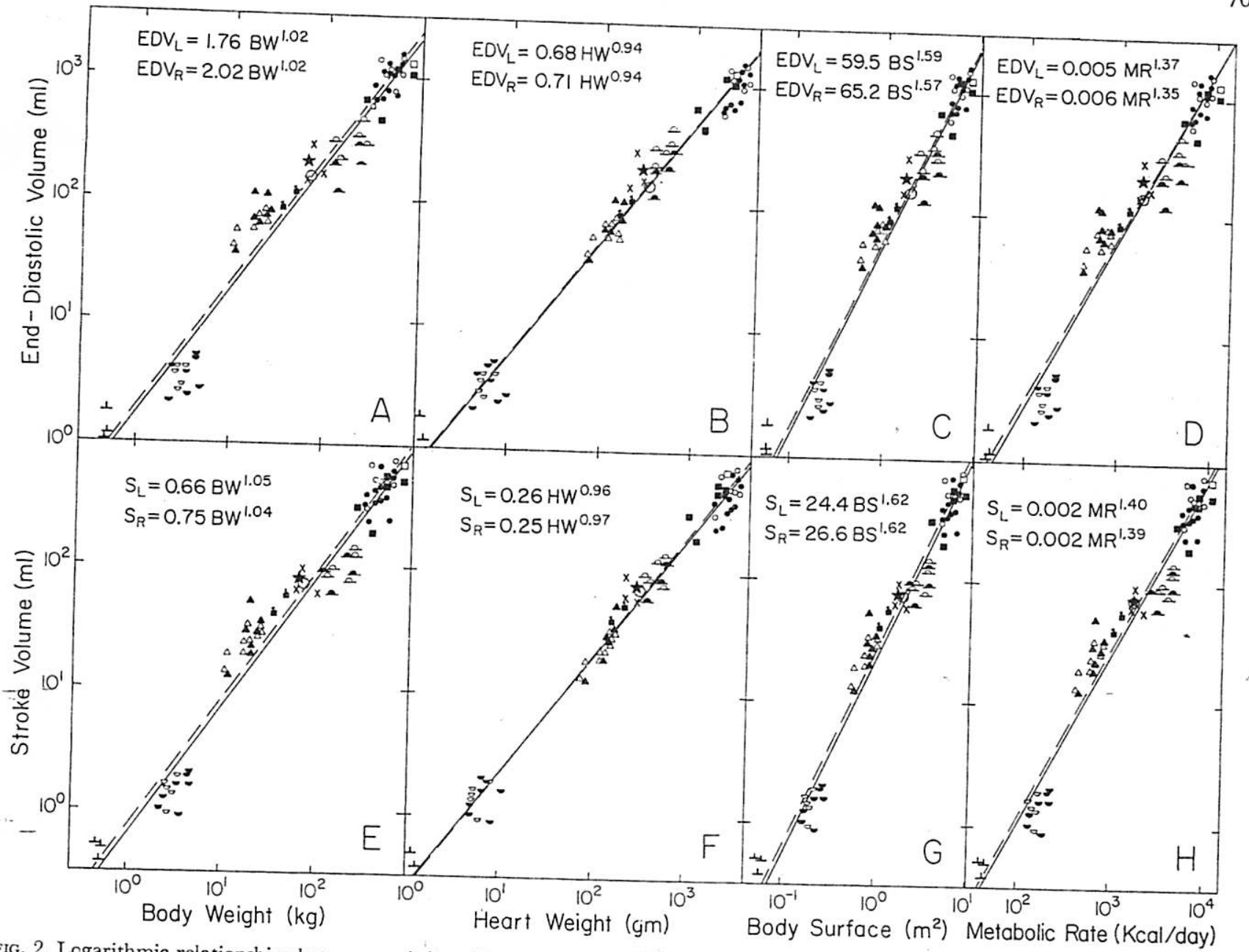

FIG. 2. Logarithmic relationships between end-diastolic volume, rroke volume and body weight, heart weight, body surface area, and metabolic rate for the right and left ventricles of nine species of mammals (rat to horse) in the control state. Solid line, left

The equations describing these relationships are:

$$
\begin{array}{ll}
\mathrm{R}_{\mathrm{L}}=236 \mathrm{BW}^{-0.25} & \mathrm{R}_{\mathrm{R}}=240 \mathrm{BW}^{-0.26} \\
\mathrm{R}_{\mathrm{L}}=322 \mathrm{HW}^{-0.24} & \mathrm{R}_{\mathrm{R}}=336 \mathrm{HW}^{-0.25}
\end{array}
$$

There was moderate scatter of the data, one standard deviation being $\pm 27 \%$ and $\pm 20 \%$, respectively, for $\mathrm{BW}$ and $\mathrm{HW}$. In contrast to the above equations, in which body weight is raised to the minus $0.25 \pm 0.01$ power, heart rate is related to body surface area raised to the minus $0.40 \pm 0.02$ and metabolic rate to the minus $0.34 \pm 0.01$ power (Table 1).

Cardiac output, body weight, heart weight, body surface, and metabolic rate. The logarithmic relationships between cardiac output and: body weight, heart weight, body surface, and metabolic rate, extending over a 156- and 60 -fold range in cardiac output for the left and right ventricles, respectively, are shown in Fig. 4 and Table 1. The equations describing these relationships are:

$$
\mathrm{CO}_{\mathrm{L}}=166 \mathrm{BW}^{0.78}
$$

$\mathrm{CO}_{\mathrm{L}}=89.2 \mathrm{HW}^{0.70}$ ventricle; broken line, right ventricle. Subscripts $L$ and $R$ are for the same as in Fig. 1.

$$
\begin{aligned}
\mathrm{CO}_{\mathrm{L}} & =2504 \mathrm{BS}^{1.21} & & \mathrm{CO}_{\mathrm{R}}=2625 \mathrm{BS}^{1.21} \\
\mathrm{CO}_{\mathrm{L}} & =1.91 \mathrm{MR}^{1.05} & & \mathrm{CO}_{\mathrm{R}}=2.12 \mathrm{MR}^{1.05}
\end{aligned}
$$

It appears that cardiac output is more nearly directly proportional to metabolic rate, in which case the power is 1.05 , than to body surface, in which case the power is 1.21 .

Stroke work, body weight, heart weight, and EDV. The logarithmic relationships between stroke work and: body weight, heart weight, ventricular weight, and EDV are these relationships are:

$$
\begin{array}{ll}
\mathrm{SW}_{\mathrm{L}}=0.59 \mathrm{BW}^{1.15} & \mathrm{SW}_{\mathrm{R}}=0.12 \mathrm{BW}^{1.14} \\
\mathrm{SW}_{\mathrm{L}}=0.29 \mathrm{HW}^{1.01} & \mathrm{SW}_{\mathrm{R}}=0.05 \mathrm{HW}^{1.01} \\
\mathrm{SW}_{\mathrm{L}}=0.45 \mathrm{VW}_{L^{1.00}} & \mathrm{SW}_{\mathrm{R}}=0.26 \mathrm{VW}_{\mathrm{R}}^{0.99} \\
\mathrm{SW}_{\mathrm{L}}=0.52 \mathrm{EDV}_{L^{1.05}} & \mathrm{SW}_{\mathrm{R}}=0.08 \mathrm{EDV}_{\mathrm{R}^{1.08}}
\end{array}
$$

As shown for the left ventricle in Table 1 there was less scatter of the data in the relationships between stroke work the relationships between stroke work and body weight the left and right ventricles, respectively. Definition of symbols is shown in Fig. 5 and Table 1. The equations describing and EDV, ventricular weight and heart weight than in 


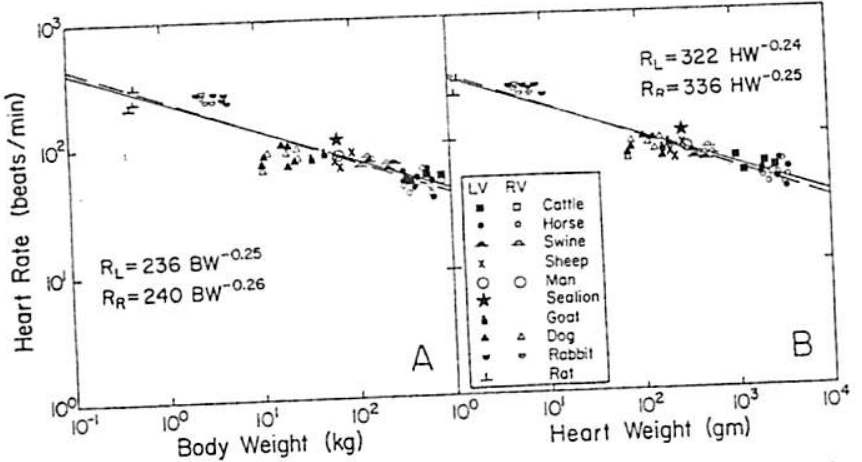

FIG. 3. Logarithmic relationships between heart rate and body weight and heart weight for the right and left ventricles of nine pecies of mammals (rat to horse) in the control state. Solid line, species of mammals (rat to bright ventricle. Subscripts $L$ and $R$ are for the left and right ventricles, respectively. metabolic rate and body surface. In contrast, in the case of the right ventricle, the scatter was less in the relationships between stroke work and body weight, metabolic rate and body surface than in the relationships between stroke work and heart weight, ventricular weight and EDV. In addition the average stroke wo $k$ per gram of heart weight and per gram left ventricular weight was 0.33 and $0.47 \mathrm{~g}-\mathrm{m}$, respectively, for the left ventricle, whereas it was only 0.06 and $0.28 \mathrm{~g}-\mathrm{m}$ for the right ventricle. The reason for these differences in the right and left ventricles is not clear, but it suggests that the mechanism of ejecting the stroke volume may be different for the two ventricles.

Total peripheral resistance and body weight. The logarithmic relationship between total peripheral resistance and body weight is shown in Fig. 6 . The equation describ-

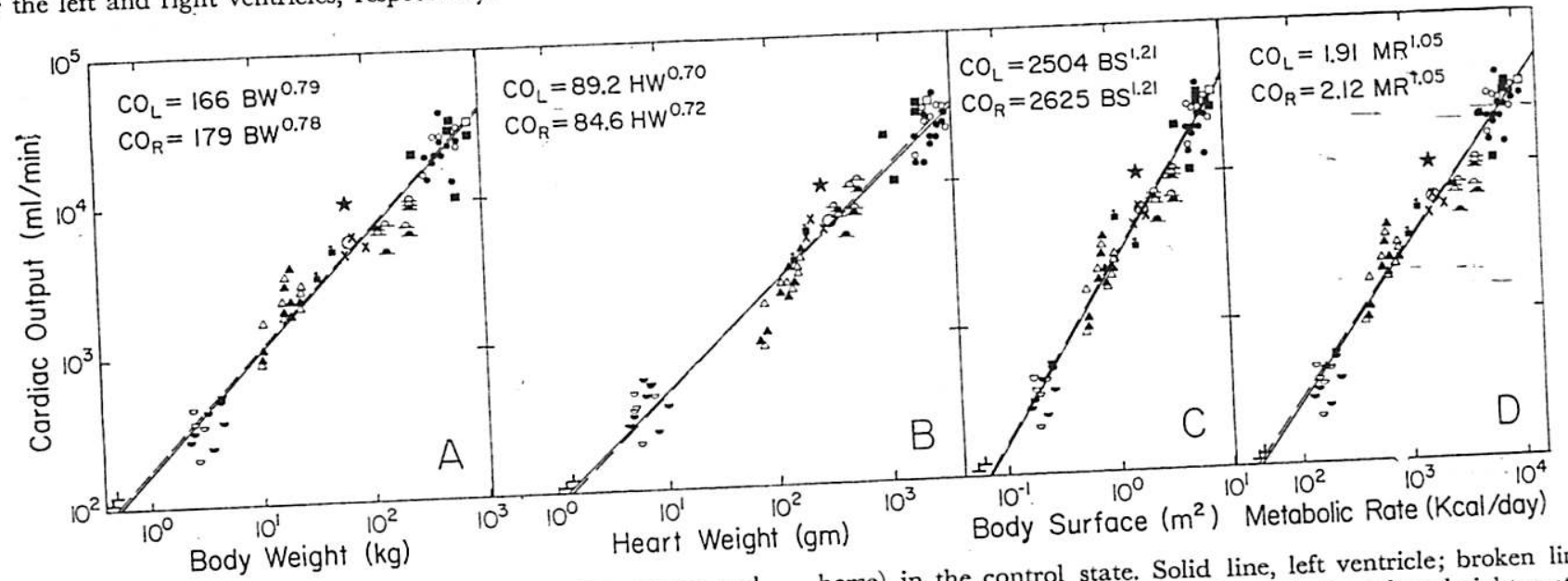

FIG. 4. Logarithmic relationships between cardiac output and in the control state. Solid line, left ventricle; broken line Dody weight, heart weight, body surface area, and metabolic rate or the right and left ventricle of nine species of mammals (rat to right ventricle. Subscripts $L$ and $R$ are for the left and right ventr cles, respectively. Definition of symbols is the same as in Fig.

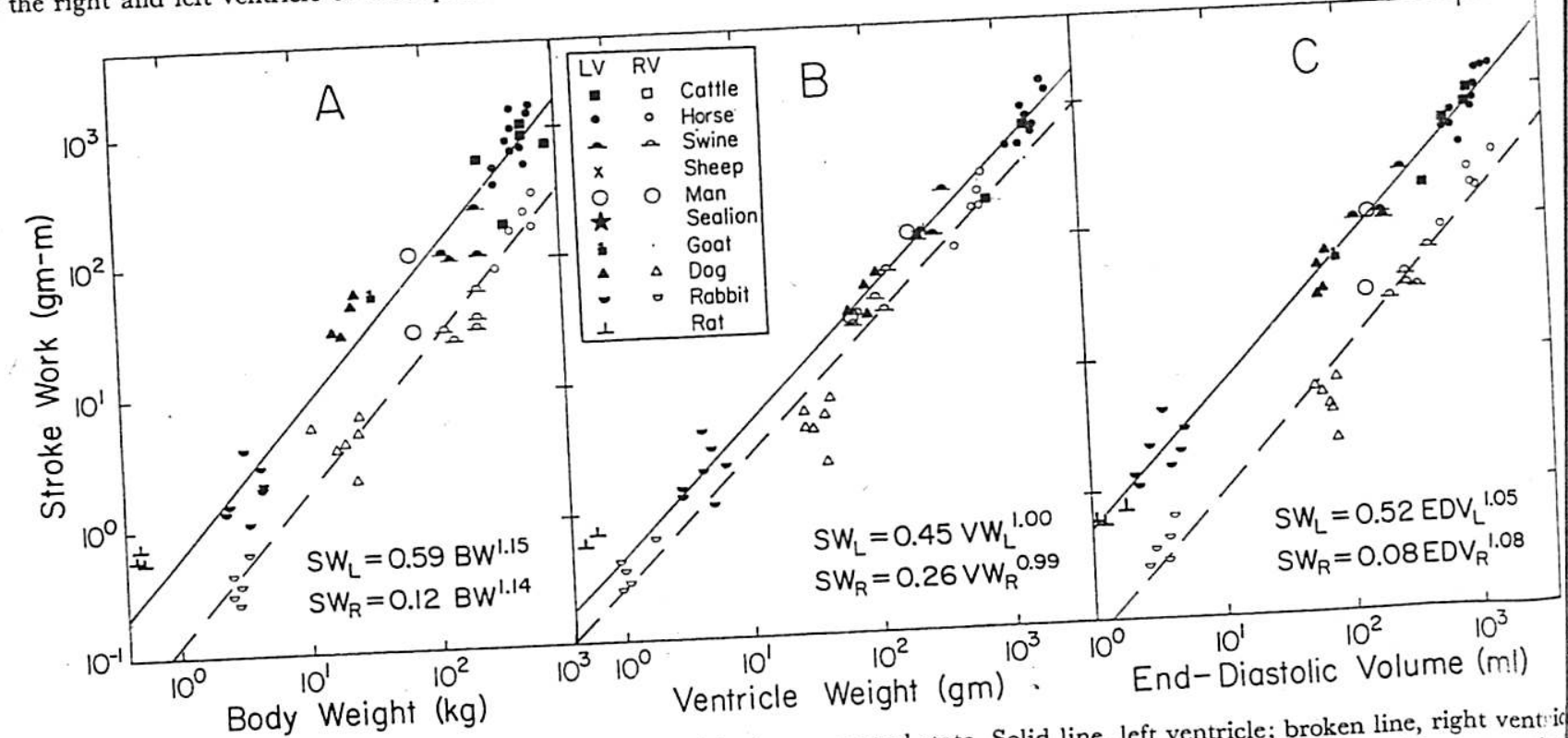

FIG. 5. Logarithmic relationships between stroke-work and body weight, ventricular weight, and end-diastolic volume for the right control state. Solid line, left ventricle; broken line, right vent Sor the left and right ventricles, respective The
devi;
of ca
alus
qua
eig.
espe
He
gar
eart
$B$. and left ventricles of nine species of mammals (rat to horse) in the 


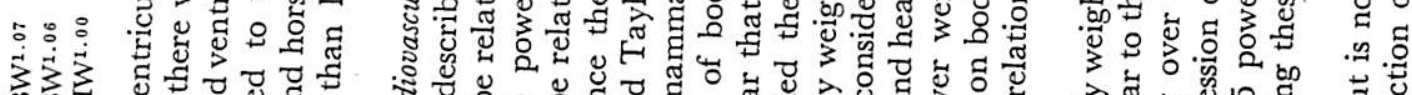

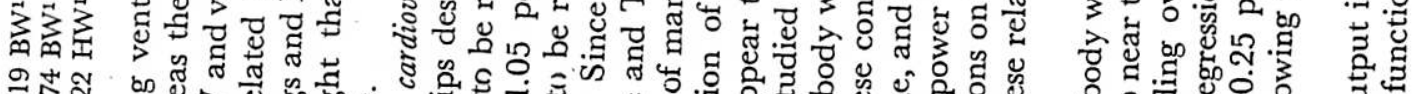

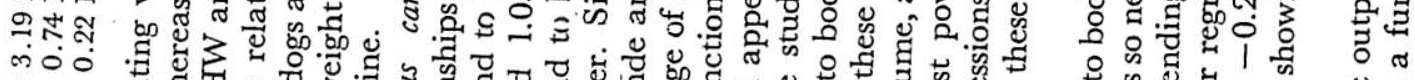

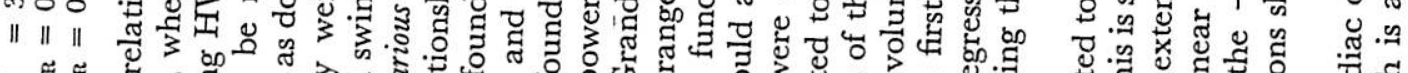

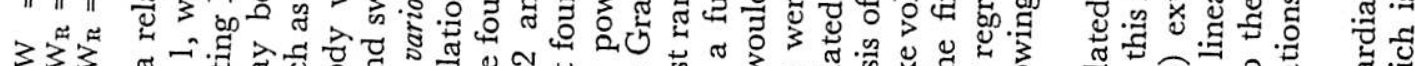

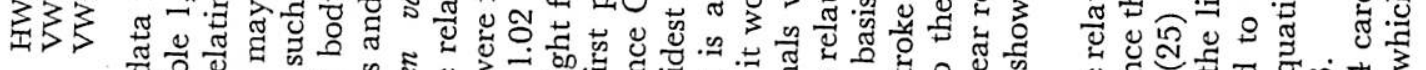

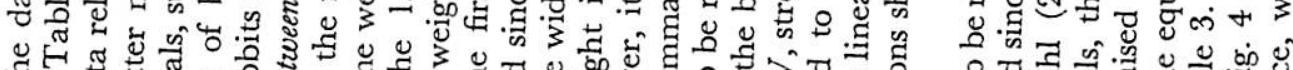

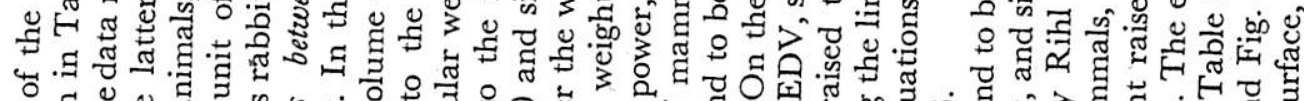

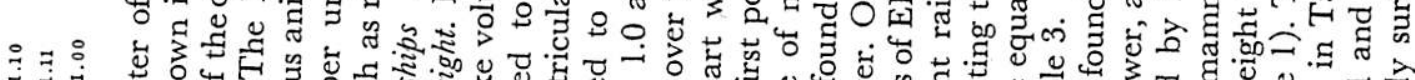

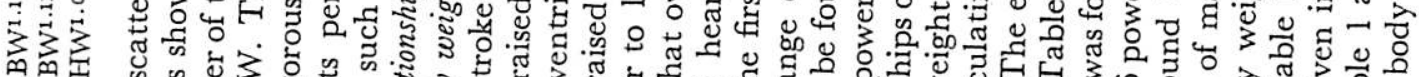

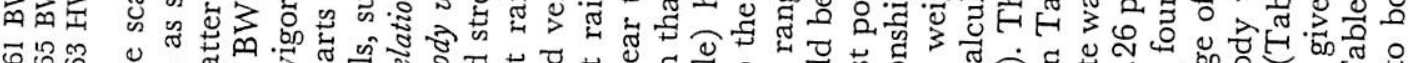
人.

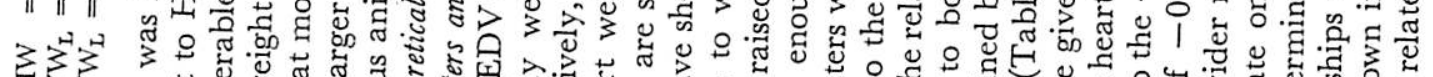

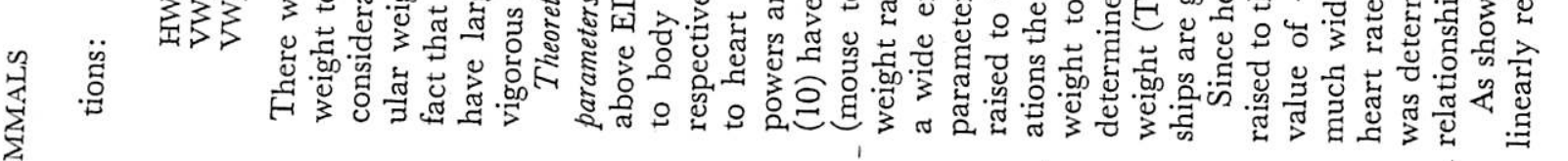
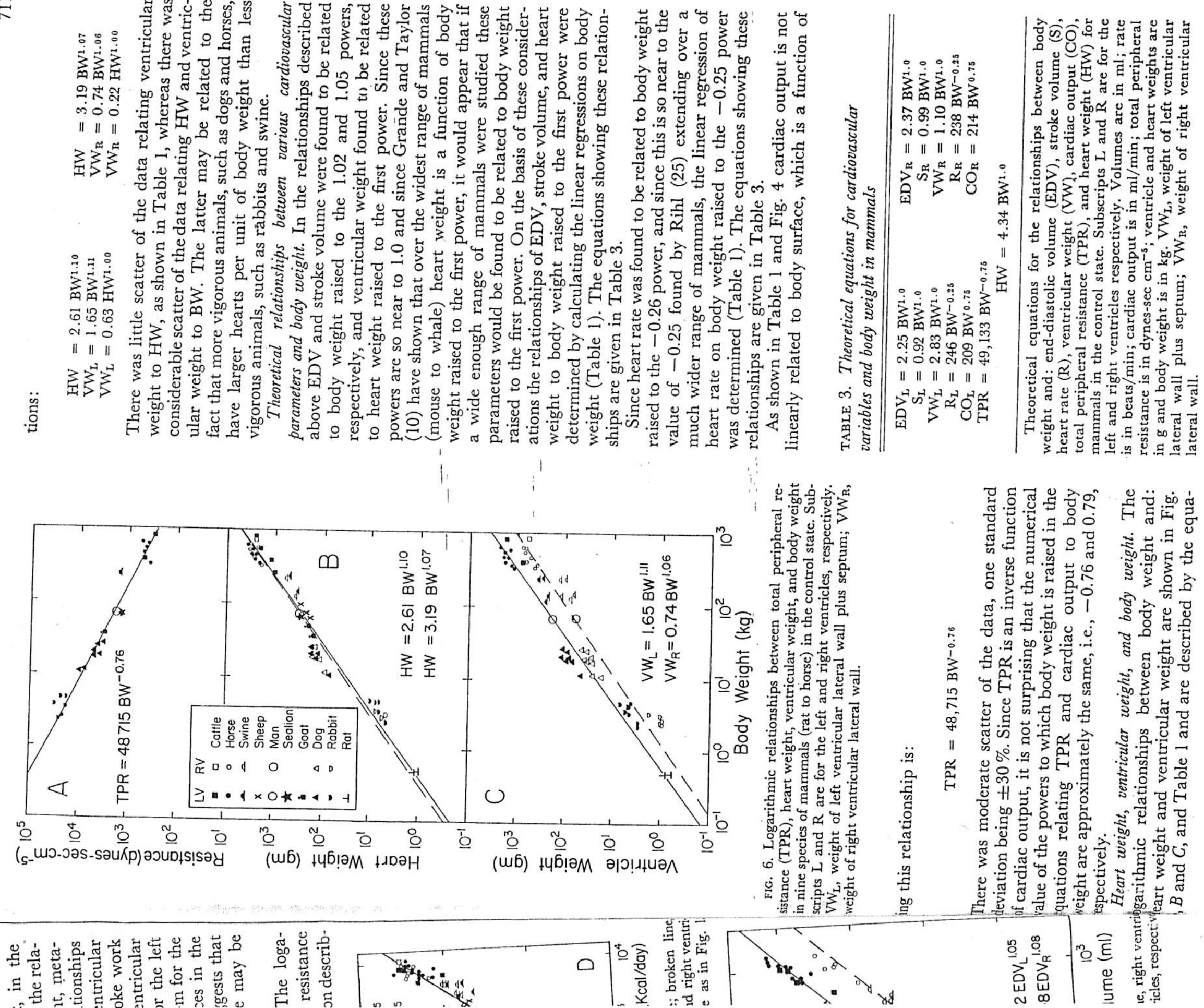
body weight raised to the 0.67 power, but is related to body weight to the 0.785 power. Since this power is very near to 0.75 and since it is generally thought that cardiac output is directly related to metabolic rate, which is a function of $\mathrm{BW}^{3 / 4}(22)$, the linear regression of cardiac output on $\mathrm{BW}^{0.75}$ was determined (Table 1). The equations showing these relationships are given in Table 3. Likewise, since TPR is equal to mean aortic pressure divided by cardiac output, and since aortic pressure is approximately the same in all mammals, it follows that TPR is a function of body weight raised to the -0.75 power, i.e.:

$$
\begin{aligned}
\text { resistance } & =\frac{\mathrm{P}}{\mathrm{CO}} \\
\frac{\mathrm{P}}{\mathrm{CO}} & \propto \mathrm{PBW}^{-0.75}
\end{aligned}
$$

Therefore:

$$
\text { resistance } \alpha \mathrm{PBW}^{-0.75}
$$

where $\mathrm{P}$ is mean aortic pressure. The linear regression of TPR on body weight raised to the -0.75 power was determined (Table 1), and the equation describing this relationship is given in Table 3 .

It will be noted in Table 1 that the standard deviations of all of the linear regression equations shown in Table 3 do not differ greatly from the standard deviations of the similar log-log relationships. It appears reasonable to believe that, if a wide enough range of mammals were studied, the relationships of the various cardiovascular variables to body weight would be described by the equations in Table 3.

\section{DISCUSSION}

On the basis of the data presented it seems clear that in the control state EDV, ESV, and stroke volume are directly related to body weight and not to body surface. Additional evidence supporting this view is the fact that if the normal value of EDV is taken to be $89 \mathrm{ml} / \mathrm{m}^{2}$ for each ventricle, as has been reported for the left ventricle of man (1), and the blood volume is taken to be $7.2 \%$ of body weight (4), then the heart of al6-ton elephant would contain less than $1 \%$ of its total blood volume, while the heart of a 13-g mouse would contain $100 \%$ of of its blood volume! Also, since heart rate is proportional to $\mathrm{BW}^{-0.25}$, if it is assumed that stroke volume is proportional to body surface, i.e., $\mathrm{BW}^{2 / 3}$, then cardiac output, which is the product of stroke volume and heart rate, would equal:

$$
\begin{gathered}
\mathrm{CO}=\mathrm{S} \times \mathrm{R} \\
\mathrm{S} \times \mathrm{R} \alpha \mathrm{BW}^{2 / 3} \times \mathrm{BW}^{-0.25}
\end{gathered}
$$

Therefore:

$$
\mathrm{CO} \alpha \mathrm{BW}^{0.42}
$$

Since the evidence is overwhelming that cardiac output is a function of body weight raised to a power greater than 0.67 , then stroke volume cannot be a function of $\mathrm{dy}$ surface.

Thus, it is clear that ventricular volumes are not a function of body surface but are a function of body weight, and it would appear desirable for investigators to report values for EDV, ESV, and stroke volume as milliliters per kilogram body weight. If this is not done, then the body weights of the animals or subjects should be given in order that other investigators may relate the volumes to body weight.

The fact that EDV was found to have a better rel ionship to heart weight than to body weight is not surprising in view of the fact that the HW/BW ratio varies widely in mammals, from $0.11 \%$ in the deer to $1.67 \%$ in the Arctic weasel (15). This is in general agreement with Clark (3), and Grande and Taylor (10) who showed that there was considerable variation of the ratio of heart weight to body weight throughout a wide range of mammals.

Since our data showing heart rate to be a function of $\mathrm{BW}^{-0.25}$ are in agreement with the data of Rihl (?5) for mammals ranging 0.5 -millionfold in body weigh and since metabolic rate per unit body weight is a function of $\mathrm{BW}^{-0.25}$, i.e. :

$$
\frac{\text { metabolic rate }}{\text { body weight }} \alpha \frac{\mathrm{BW}^{0.75}}{\mathrm{BW}^{1.0}}
$$

Therefore:

$$
\frac{\text { metabolic rate }}{\text { body weight }} \alpha \mathrm{BW}^{-0.25}
$$

It appears reasonable to conclude that heart rate is a function of metabolic rate per unit of body weight, i.e.:

$$
\text { heart rate } \alpha \frac{\text { metabolic rate }}{\text { body weight }}
$$

This is in agreement with the evidence that the frequency of rhythmic activity of various bodily processes, as for example, respiratory rate, rate of reproduction, and the rate of rhythmic intestinal activity, vary in a manner similar to the variations of metabolic rate per unit body weight $(3,29)$.

Likewise, since stroke volume is a function of body weight, i.e.:

$$
\mathrm{S} \alpha \mathrm{BW}^{1.0}
$$

It follows that cardiac output, which is the pro uct of rate and stroke volume, is related to BW and me abolic rate as follows:

$\mathrm{CO}=\mathrm{S} \times \mathrm{R}$

$\mathrm{S} \times \mathrm{R} \propto \mathrm{BW}^{1.0} \times \mathrm{BW}^{-0.25}$ 
Therefore:

rr than

f body

not a

$\vdots$ bo y

tors to

me as

: done, should

relate

lation-

prising widely in te it with ihowed if heart :mam-

:tion of 25) for it, and :tion of

te is a at, i.e.:

quency as for ind the nanner it ody if body

tuct of tabolic

Therefore: state. and, as shown above:

$$
\mathrm{CO} \alpha \mathrm{BW}^{0.75}
$$

$$
\mathrm{MR} \alpha \mathrm{BW}^{0.75}
$$

That is, cardiac output is the same function of body weight as is metabolic rate and would appear to be a function of metabolic rate. This is supported by the fact that in an individual animal cardiac output is proportional to the rate of oxygen consumption in muscular exercise (13). It appears that the adjustment of cardiac output to basal metabolic rate in the 30 -millionfold range in body size of mammals, from the shrew to the whale, is brought about by the fact that stroke volume is directly related to $\mathrm{BW}^{1.0}$, while heart rate is related to metabolic mammal, which weight, i.e., $\mathrm{BW}^{-0.25}$. Thus, the small to main, which must have a high metabolic rate in order to maintain body temperature constant, adjusts heart rate proportional to its high metabolic rate per gram body weight, and the product of the rate and the stroke volume give a cardiac output that is proportional to $B W^{0.75}$, i.e.:

$$
\begin{aligned}
& \mathrm{CO}=\mathrm{S} \times \mathrm{R} \\
& \mathrm{S} \times \mathrm{R} \alpha \mathrm{S} \times \frac{\text { metabolic rate }}{\text { body weight }} \\
& \mathrm{S} \times \frac{\text { metabolic rate }}{\text { body weight }} \alpha \mathrm{BW}^{1.0} \times \frac{\mathrm{B} W^{0.75}}{\mathrm{BW}^{1.0}}
\end{aligned}
$$

$$
\mathrm{CO} \propto \mathrm{BW}^{0.75}
$$

These results, showing cardiac output to be a funcuion of $\mathrm{BW}^{0.75}$ are in contrast to the results reported by Patterson et al. (24) that over a range of mammals extending from the dog to the giraffe, cardiac output was directly related to $\mathrm{BW}^{1.0}$. The reason for this difference in results is not clear. Evidence has been presented that apprehension increases cardiac output (13), and tized, it mast the animals in that study were unanesthe-

Since all mammals, with the exception of the giraffe, have an arterial pressure of approximately $130 / 80 \mathrm{~mm}$ $\mathrm{Hg}$, and since stroke volume is a function of $\mathrm{BW}^{1.0}$, it vould be expected that stroke work per unit body weight would be a constant because:

$$
\mathrm{SW}=\mathrm{S} \times(\text { mean aortic pressure })
$$$$
\mathrm{S} \times \text { (mean aortic pressure) } \alpha \mathrm{BW}^{1.0} \times \text { constant }
$$

herefore:

SW $\alpha$ BW $^{1.0} \times$ constant
Dividing by $\mathrm{BW}^{1.0}$ :

$$
\begin{aligned}
& \frac{\mathrm{SW}}{\mathrm{BW}} \alpha \frac{\mathrm{BW}^{1.0}}{\mathrm{BW}^{1.0}} \times \text { constant } \\
& \frac{\mathrm{SW}}{\mathrm{BW}^{1.0}}=\text { constant }
\end{aligned}
$$

Likewise, since $\mathrm{HW}^{1.0}$ is proportional to $\mathrm{BW}^{1.0}$ it follows that stroke work per gram of heart weight is a constant. This is in agreement with our results in mammals whose left ventricular varied 3,181-fold (rat to horse) in which $\mathrm{HW}$.

It should be emphasized that the data given here are for adult animals varying greatly in size and extending over many species. The relationships, we believe, formulate the similarity criteria which define the normal adult mammalian design of the cardiovascular functions studied. That the relationships may be different within one species, when maturating animals as well as adults are included, has been pointed out by Stahl (29) and is shown by Gleason's analysis of Müller's data on the relationship of heart weight to body weight (10). In growing and adult human males, whose body weight varied from less than 1.5 to more than $100 \mathrm{~kg}$, heart weight was found to be a function of BW ${ }^{0.93}$ instead of of $\mathrm{BW}^{1.0}$ as reported here. This is in agreement with the data of Smith (27) showing that in infants under 1 year of age the heart weight-to-body weight ratio is approximately twice that of adults. Clark (3) earlier presented similar evidence for lower animals. Thus, the equations

presented here can be expected to be somewhat different
in growing animals.

To what degree the constant and/or power function may vary in describing the relationships within a single adult species, such as man, is not known. That there is a variation from species to species is clear, as for example the ratio of heart weight to body weight of the dogs in the present study was $7.0 \mathrm{~g} / \mathrm{kg}$ while that of the relatively inactive rabbits was 1.9. In the absence of data extending over a wide range of body size in an individual species it would appear reasonable to assume that the power functions obtained in the present study describe the relationships within each species, but that the constants may vary from species to species. The relationships described show less variability when related to heart weight than when related to body weight, and a correction procedure can be employed for individual species based on the HW/BW ratio of that species. As for example, on the basis of the equation for the relationship of EDV to body weight
(Table 3):

$$
\mathrm{EDV}_{\mathrm{L}}=2.25 \mathrm{BW}^{1.0}
$$

calculation of the predicted EDV by this equation for each of the dogs in the present study gave values which, when compared to the measured end-diastolic volumes, were in error by an average of $-38 \%$. This error is 
reduced by multiplication of the above constant by a "species correction" constant which is defined as the ratio of the average HW/BW ratio of the particular species to the average $\mathrm{HW} / \mathrm{BW}$ ratio of all mammals. As shown in Table 2 the average $\mathrm{HW} / \mathrm{BW}$ ratio of the dogs studied was 7.0, while from the equation in Table 3 relating heart weight to body weight the HW/BW ratio for all mammals studied was 4.34 . Thus for dogs,

$$
\begin{aligned}
& \mathrm{EDV}=2.25\left(\frac{7.0}{4.34} \mathrm{BW}\right)^{1.0} \\
& \mathrm{EDV}=3.63 \mathrm{BW}^{1.0}
\end{aligned}
$$

Using this corrected equation the average error of the predicted EDV of the dogs in this study was $\pm 21 \%$. This same correction procedure can be employed for the calculation of stroke volume for animals in any mammalian species provided values for the HW/BW ratio are available for that species.

It should be pointed out that all of the results reported here for the right ventricle and $78 \%$ of the determinations on the left ventricle were obtained on anesthetized animals. Although no individual animal was studied both in the unanesthetized and anesthetized state the values for stroke volume, EDV, and cardiac output were less in the anesthetized animals than in unanesthetized animals of similar size. However, it is felt that the number of unanesthetized animals studied was too small on which to base conclusions at the present time, and that the relationships obtained and given in the Tables should be considered to apply to anesthetized animals. There is considerable evidence showing that the anesthetics

\section{REFERENCES}

1. Bartle, S. H., and M. E. Sanmarco. Comparison of angiocardiographic and thermal washout technics for left ventricular volume measurement. Am. J. Cardiol. 18: 235-252, 1966.

2. BRODY, S. Bioenergetics and Growth. New York: Hafner, 1964 p. 370.

3. Clark, A. J. Comparative Physiology of the Heart. New York: Macmillan, 1927, p. 71, 87.

4. Courtice, F. C. The blood volume of normal animals. J. Physiol., London 102: 290-305, 1943.

5. Davila, J. C. Symposium on measurement of left ventricular volume. Am. J. Cardiol. 18: 1-42, 208-252, 566-593, 1966.

6. Dodge, H. T., H. Sandler, W. A. Baxley, and R. R. HAwLEY. Usefulness and limitations of radiographic methods for determining left ventricular volume. Am. J. Cardiol. 18: 10-24, 1966.

7. Dodge, H. T., and H. L. Tanenbaum. Left ventricular volume in normal man and alterations with disease (Abstract). Circulation 14: 927, 1956.

8. DuBors, E. F. Basal Metabolism in Health and Disease (3rd ed.). Philadelphia: Lea \& Febiger, 1936, p. 142.

9. Freis, E. D., G. L. Rivara, and B. L. Gilmore. Estimation of residual and end-diastolic volumes of the right ventricle of men without heart disease, using the dye-dilution method. Am. Heart J. 60: 898-906, 1960.

10. Grande, F., And H. L. TAylor. Adaptive changes in the heart, vessels, and patterns of control under chronically high loads. Handbook of Physiology. Circulation. Washington, D.C.: Am. Physiol. Soc., 1965, sect. 2, vol. III, chapt. 74, p. 2615-2677. employed decrease cardiac output. As a result ca output values obtained in this study can be expect be less than those in the unanesthetized anim?! anesthesia in general increases heart rate, and th the heart rates in the data reported here are in "normal" range, many of these were near the $t$ limit of normal. There is also the possibility anesthesia decreases the contractility of the heart, as a result decreases the ejected fraction. Therefor values for ESV and residual fraction may be greater they would be in the unanesthetized animal. Thu equations reported here concerning the various ca vascular variables would be expected to be some different in the unanesthetized state. Since th $f$ anesthesia would be expected to have approsim the same proportional depressing effect on a wide va of mammals, the power to which body weight is ra in the equations-relating the various cardiovas parameters to body weight, would be expected to b same in the unanesthetized as in the anesthetized ani however, the constants in the power law equations w be expected to be somewhat different.

The authors express their thanks to A. Garfein, R. Tield Ott, B. Thomas, J. Byrn, W. Powell and W. Sholes 1 tech assistance, and to $\mathrm{K}$. Shotts for assistance in preparing the grams for the computer.

This investigation was supported, in part, by the Kent Louisville, and Jefferson County Heart Associations, Public H Service Research Grants 2075 and HE5622 from the Nat Heart Institute, and by Institute for Comparative Biology, Diego Zoological Gardens. Preliminary communications published in Physiologist 9: 205, 1966, and 10: 221, 1967.

Received for publication 6 February 1968.

11. Greisheimer, E. M. The circulatory effects of anesth Handbook of Physiology. Circulation. Washington, D.C.: Am.Ph Soc., 1965, sect. 2, vol. III, chapt. 70, p. 2477-2510.

12. Grollman, A. Physiological variations in the cardiac of of man. VI. The value of the cardiac output of the no individual in the basal, resting condition. Am. J. Physiol 210-217, 1929.

13. Guyton, A. C. Circulatory Physiology: Cardiac Output an Regulation. Philadelphia: Saunders, 1963, p. 11.

14. Hamilton, W. F., ANd J. W. Remington. Some facto the regulation of the stroke volume. Am. J. Physioi 153: 297, 1948.

15. Handbook of Circulation, edited by D. S. Dittmer and $\mathrm{R}$ Grebe. Philadelphia: Saunders, 1959, p. 25.

16. Harris, J. A., AND F. G. BENEDICT. A biometric study of metabolism in man. Carnegie Inst. Wash. Publ. 279: 1-266,

17. Hoist, J. P. Estimation of the residual volume of the vent of the dog's heart by two indicator dilution technics. Circul Res. 4: 187-195, 1956.

18. Holt, J. P., AND J. Allensworth. Estimation of the resic volume of the right ventricle of the dog's heart. Circulation. 5: 323-326, 1957.

19. Holt, J. P., E. A. Rhode, S. A. Peoples, and H. Kines. ventricular function in mammals of greatly di rent Circulation Res. 10: 798-806, 1962.

20. Kines, H., AND J. P. Holt. Left ventricular volumes in rab (Abstract). Federation Proc. 22: 521, 1963.

21. KLEIBER, M. Body size and metabolism. Hilgardia $6: 315-$ 1932. 


\section{IND KINES}

iult cardiac expected to imal. Also, d althongh are

the upper bility that heart, and erefore the reater than . Thus the ous cardiosomewhat re effect of roxi 'ely ride . iety It is raised, tiovascular $\mathrm{d}$ to be the :ed animal; ions would

$\therefore$ Fields, D for technical inf e pro-

= Kentucky ublic Health he National 3iology, San ations were 1967

sthetics. $\therefore$ in. Physiol. diac output the normal Physiol. 90: :tput and Its e factors in I. 153: 287-

nd R. M. 1 dy of basal $-266,1919$ he ventricle i. Circulation he residual culation Res.

KINES. Left ferent size. $i$ in rabbits ;: $315-353$

\section{VENTRICULAR VOLUMES AND BODY WEIGHT IN MAMMALS} 22. KLEIBER, M. Body size and metabolic rate. Physiol. Rev. 27 :
$511-541,1947$.

26. SAPIRTEIN, L. A 715 the albino rat. $A m$. $J$. Phy . Goldman. Adrenal blood flow in cardial function and W. KIRKLIN, AND H. J. C. Swan. Myovalvular insufficiency. ventricular volumes in acquired

24. Patterson, J. L., JR., Rirculation 31: 374-384, 1965. Warren, O. H. Gauer, H. Goetz, J. T. Doyle, J. V. Hoernicke, M. McGreger D. K. Detweiler, S. I. SAid, H. E. L. HARdie, M. REYNolds, W. N. KeEN, M. H. SMTth, JR., Cardiorespiratory dynamics in the FLATT, AND D. R. WALDO. parative observations on $\mathrm{man}$ the ox and giraffe, with comAcad. Sci. 127: 393-413, 1965 . R

und pathologischen Physiologie. Berlin. Sandbuch der normalen sect. 1, p. 449-457.
27. Smrth, H. L. The J. Physiol. 196: 159-162, 1959. weight of the body and of the weight of the heart to the Am. Heart J. 4:79-93, 1928.

28. Sulvar, H. 1928. Heart J. 72: 621-631, 1966 .

29. STAH $W$.

J. Appl. Physiol. 22: 453-460, 1967 variables in mammals.
J 30. Wust. 22: 453-460, 1967.

ously recording conductivity of cardiac output by a continu45-57, 1947. and R. H. H. A. Vincent, U. Kashe msant, R. P. Cuddy,

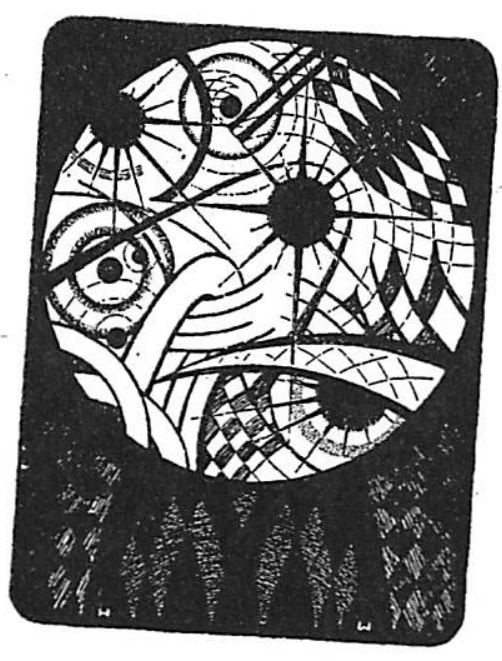

